\title{
Hox Genes and Teratogenic Factors
}

\author{
Takuya Kojima and Naoki Takahashi \\ Department of Applied Biological Chemistry, \\ Graduated School of Agricultural and Life Sciences, \\ University of Tokyo, \\ Japan
}

\section{Introduction}

Exposure to a variety of chemicals is a hazard of daily life. Some of these chemicals have teratogenic potency and may lead to social problems. As an example, thalidomide was prescribed as a sedative and for morning sickness in the late 1950s and caused serious embryonic effects worldwide. To avoid these problems, the development of efficient techniques for the detection of teratogenic substances contained in various chemical compounds is desired. Detection of teratogenic effects using various experimental animals is only partially effective because different phenotypes occur among species. Therefore, effective methods for the detection of teratogenic factors must be based on their molecular mechanisms. However, knowledge of the molecular mechanisms that lead to the different phenotypes caused by teratogenic factors is limited, and useful molecular markers for these factors are not known.

Approximately 30,000 genes in higher organisms are expressed under strict control. This regulation of expression is mainly dependent on transcription factor networks. In higher organisms, there are about five hundred transcription factors that contain a DNA-binding domain and cooperate in the regulation of the expression of downstream genes. Alterations in these regulatory mechanisms result in a variety of problems. In the case of teratogenic factors, abnormal morphogenesis is one of the common findings in exposed embryos. Developmental abnormalities including skeletal malformations, cleft palates, neural tube defects, and cardiovascular anomalies have been found to have a similar causative mechanism, which was revealed in loss- or gain-of-function studies of the transcription factors involved in morphogenesis. The information from genetic analyses is important for the understanding of the molecular mechanism of teratogenic effects.

The present chapter discusses the transcription factors involved in morphogenesis (Hox, Tbox family, and other homeo-box genes) and the deleterious agents that lead to congenital malformations, and the link between them is explored. We also present recent findings from our group and provide guidelines for the prevention of the risks associated with environmental contaminants. In addition, we speculate on the molecular mechanisms of congenital malformation. 


\section{Transcription factors for development}

The individual cells that make up multi cellular organisms acquire a wide variety of positional information cues from body axes. This local information leads to the formation of tissues and organs and is essential for the maintenance of homeostasis. There are three fundamental axes in multi cellular organisms: anterior-posterior, dorso-ventral, and proximal-distal. Abnormalities in body axis formation caused by genetic or external factors can lead to the development of lesions. Certain transcription factors play critical roles in body axis patterning, along with a wide variety of diffusible factors such as growth factors, BMPs, sonic hedgehog.

In this section, we refer to several transcription factors involved in body axis formation.

\subsection{Hox genes}

\subsubsection{Overview of Hox genes}

Hox genes encode transcription factors that play important roles in the process of morphogenesis along the anterior-posterior axis of the body. In the early 1900s, Morgan and Bridges found abnormal body plan mutants such as the replacement of antennae with legs in Drosophila melanogaster. These morphological abnormalities may have been caused by alterations in the expression of genes that contain a characteristic sequence (homeo-box), which were described in 1970. The homeo-box sequence encodes 61 amino acids designated as the homeo-domain and composed of a helix-turn-helix. Through the activity of this homeo-domain, Hox proteins bind a core consensus sequence ( $5^{\prime}$-TAAT- $\left.3^{\prime}\right)$ in target genes and function as transcriptional activators or repressors. In the regulation of the expression of various downstream genes, Hox proteins function as monomers, homodimers, heterodimers, or heterotrimers with cofactors such as Meis or Pbx family proteins (Moens and Selleri, 2006). Hox genes are highly conserved across species. In the nematode Caenorhabditis elegans, there are seven Hox genes in chromosome III that are distributed in intervals of $3.9 \mathrm{Mb}$. In the fly Droshophila melanogaster, eight Hox genes are clustered in chromosome $3 \mathrm{R}$, which is referred to as the homeotic complex (HOM-C), and they are located across long interval regions consisting of $9.5 \mathrm{Mb}$. Hox genes are also clustered between $100 \mathrm{~kb}$ regions in the mammalian genome but this cluster is tandem duplicated; there are four clusters in the mouse (chromosomes 7, 17, 12, and 2) and humans (chromosomes 6, 11, 15, and 2). These separate clusters are termed Hox A, B, C, and D, respectively.

In normal vertebrate development, there are three important features of Hox gene expression. First, the genomic locations reflect the expression in the A-P axis. Generally, 3' genes are expressed in anterior tissues and $5^{\prime}$ genes in posterior tissues. This phenomenon is termed "spatial colinearity". Second, 5' located Hox genes will have a dominant phenotype to more 3' located Hox genes. This is referred to as "posterior prevalence". The third feature is "temporal colinearity"; 3' located Hox genes in the cluster are expressed earlier than $5^{\prime}$ located Hox genes (Mallo et al., 2010). These properties are under strict expressional control; actually a wide range of factors are involved in the control of Hox gene expression. A common mechanism of regulation of Hox expression is epigenetic control. In general, the silencing of genes is mediated by histone modifications such as the methylation of the promoter region. Polycomb and trithorax group proteins are important modulators of 
histone trimethylation. The polycomb group and trithorax complexes trimethylate lysine 27 of histone H3 (H3K27) and lysine 4 of histone H3 (H3K4), respectively (Mendenhall and Bernstein, 2008). These histone modifications can be reflected in gene expression states such as inactive in $\mathrm{H} 3 \mathrm{~K} 27 \mathrm{~m} 3$ or active in $\mathrm{H} 3 \mathrm{~K} 4 \mathrm{~m} 3$. In undifferentiated pluripotent cells, two modifications are found in some local regions and are described as a bivalent chromatin domain (Bernstein et al., 2006). These chromatin modifications lead to changes in the accessibility of trans-acting factors that bind to cis-elements. The expression of Hox genes is regulated by a wide variety of trans-acting factors: Hox (self-, palalogus-, and another family gene) and other types of transcription factors (Cdx, Rar/Rxr, etc: see below).

Second, small or large RNAs that are independent of protein synthesis regulate Hox gene expression. In the Hox cluster, there are three miRNA families, namely mir-10, mir-196, and mir-615. These miRNAs are conserved between the fly and humans. Generally, miRNAs have been thought to influence the target mRNA stability and translation. In mammalians, at least 30 of the 39 Hox 3' UTRs have one or more conserved matches to miRNAs like mir196. The expression of these mir-10 and mir-196 families is complementary to Hox gene expression (Mansfield et al., 2004) and is closely linked to posterior prevalence (Hornstein et al., 2005; Yekta et al., 2004). The number of registered miRNAs has recently reached more than 16,000 (miRBase, release 17), suggesting that other miRNAs from outside the Hox cluster may contribute to the regulation of Hox gene expression. LncRNAs (long noncoding RNAs), which range from several hundred bases to dozens of kilobases, are another type of RNA polymerase II transcribed RNA with a different function from a template for protein synthesis. Xist, known as a regulator of parental-specific expression of imprinting genes, is cited as one example (Augui et al., 2011). There are two lncRNAs transcribed from both sides of the HoxA cluster. Hottip, transcribed from the $5^{\prime}$ site of HoxA13, and Hotairm1, transcribed from between HoxA1 and HoxA2, are the recently reported lncRNAs that lead to conformational changes in chromatin together with the transcribed Hox gene RNA (Rinn et al., 2007; Wang et al., 2011).

The regulation of the expression of the Hox cluster genes occurs through a wide variety of mechanisms, and irregularities in this regulation can result in several abnormalities as described in the following sections.

\subsubsection{Phenotypes of Hox mutants}

Loss or gain of function Hox mutants show homeotic transformations across species. The identity of body segments is determined by specific combinations of Hox gene expression known as the "Hox-code". Alterations in the Hox-code result in abnormalities in morphogenesis along the longitudinal (A-P) axis of the body, termed homeotic transformation. For example, loss of function of the labial gene in the fly, which is located in the $3^{\prime}$ region of the cluster, results in the disorganization of cranial structure, which is seen in the formation of the salivary glands. The antennapedia mutant is characterized by the replacement of antennae by legs (Hughes and Kaufman, 2002). The HOM-C complex is formed by two gene clusters, the antennapedia complex (ANT-C) and the bithorax complex $(B X-C)$. These two complexes are encoded in the same chromosome but are separated by 9.5 $\mathrm{Mb}$. Genetic analyses have shown that ANT-C determines the specificity of the anterior thoracic and head regions, and $B X-C$ determines the posterior thoracic segments and the abdomen. 
In higher organisms, there are 39 known Hox genes and the analysis of their function has become increasingly more complex. The analysis of the function of mammalian Hox genes in vivo has been carried out through the generation of a large number of Hox gene knockout or knock-in mice. These mice frequently show skeletal abnormalities such as alterations in the number of thoracic segments. These phenotypes are explained as resulting from aberrances in the Hox-code (Wellik, 2009). Dramatic phenotypes, such as the replacement of antennae by legs in the fly mutant, are not observed in single gene mutants in mammals possibly because of compensatory effects between the 39 Hox genes, especially among paralogous genes.

Individual Hox genes have specific functions in various organs. Among skeletal abnormalities, cleft palate phenotypes have been detected in Hoxa2 \% mice (GendronMaguire et al., 1993). These phenotypes have also been observed in Hoxa7 and Hoxb7 gain of function mice (Balling et al., 1989; McLain et al., 1992).

The expression of Hox genes belonging to paralog groups 9 to 13 are coordinately detected during limb bud development. Among these genes, Hoxa13 and Hoxd13 in the paralog group 13 are specifically expressed in the developing distal region (the autopod). Human synpolydactyly (SPD) is a rare dominantly inherited limb malformation characterized by syndactyly between the third and fourth fingers and between the fourth and fifth toes. Typical SPD is caused by mutations of the Hoxd13 gene such as expansions, frame-shift deletions, and functional mutations (Malik and Grzeschik, 2008). Another human malformation, the hand-foot-genital syndrome (HFGS), is associated with mutations in the Hoxa13 gene (Goodman, 2002).

In addition, aberrant limb formation has been observed in Hoxa13 ${ }^{+/-}$and Hoxd13-/- mutant mice (Dolle et al., 1993; Fromental-Ramain et al., 1996). The greater severity of the phenotypes of Hoxa13+/-/Hoxd13-/- mice suggested that redundancies within paralog groups may play a role in limb development. These redundant manners are also observed in kidney formation. There are three Hox 11 paralogous genes in clusters A, C, and D. In triple mutants, metanephric induction is completely absent, and the reduction of Six 2 and Gdnf expression is believed to be one of the causative factors for this phenotype (Wellik et al., 2002). On the other hand, the activities of Hox genes within a single cluster are important for kidney formation (Di-Poi et al., 2007).

Hoxa13-/-and Hoxd13\%- mice exhibit a reduction of branching in prostate ducts; Hoxa13-/mutants die in utero with severe urinary and genital tract malformations (Podlasek et al., 1999; Podlasek et al., 1997; Warot et al., 1997). Hoxb13 also functions in ventral prostate morphogenesis. Hoxb13-/- mice exhibit transparent ducts of the ventral prostate and these abnormalities are more severe in Hoxb13-/-/Hoxd13-/- mice, which show a $50 \%$ reduction in the number of duct tips (Economides and Capecchi, 2003).

The involvement of the Hox genes described above in various morphogenetic events suggests the possible existence of a close relationship between Hox gene expression and the effects of teratogenic factors.

\subsubsection{Function of Hox genes: Proliferation, apoptosis, and differentiation}

Hox genes have different functions associated with proliferation, apoptosis, and differentiation. The Hox genes of the A, B, and C but not of the D clusters are transcribed in specific subpopulations during normal hematopoiesis. Gain- or loss-of-function analyses of 
expressed Hox genes showed their ability to specifically regulate different stages of hematopoietic development. Among them, Hoxb4 serves as a positive regulator of selfrenewal and expansion (engraftment) in hematopoietic stem cells (HSC) (Antonchuk et al., 2002; Kyba et al., 2002). On the other hand, definitive hematopoiesis was not disrupted in Hoxb4-deficient mice, but Hoxb3-//Hoxb4- mice exhibited more pronounced hematopoietic differences (Bjornsson et al., 2003; Sauvageau et al., 1995). These results suggest that a more complex mechanism, such as gene redundancy, compensatory mechanisms and crossregulatory interactions, among Hox genes may play a significant role in vivo.

Hox genes are involved in the regulation of cell proliferation, and their expression in tumor cells has therefore been studied. Certain Hox genes show aberrant expression in various tumor cells (Shah and Sukumar, 2010). These disruptions of normal Hox expression may affect various pathways linked to the promotion of tumorigenesis and metastasis. Moreover, some Hox genes (Hoxa9, 11, and 13) are fusion partners of the nucleoporin gene Nup98 in human leukemia (Moore et al., 2007). This fusion oncoprotein may play a role in modulating transcription and controls the nucleo-cytoplasmic transport of some mRNAs and proteins. Actually, the Nup98-hox fusion induces myeloproliferative disease and AML in mouse bone marrow transplantation models. Other fusion proteins such as Hoxc11 or 13 are also known to induce AML.

Tumorigenesis is often characterized by alterations in the balance between proliferation and apoptosis. When viewed from this perspective, alterations in Hox gene expression can contribute to tumorigenesis (oncogenesis) by allowing the activation or repression of the apoptosis pathway. In breast cancer cell lines, Hoxa5 directly regulates p53 expression by binding to its promoter (Raman et al., 2000). In addition, Hoxa5 induces apoptosis by promoting the expression of caspase 2 and caspase 8 in breast cancer cells in a p53independent manner (Chen et al., 2004). In the fly, Hox genes induce the localized cell death that is essential for the maintenance of a morphological boundary between the two structures of the embryo's head, namely the maxillary and mandibular head lobes. In this case, the Hox gene Deformed ( $D f d$ ) directly activates the expression of the cell death promoting gene reaper (rpr), thereby inducing localized cell death (Lohmann et al., 2002). Although it is not clear whether this apoptotic pathway is conserved in mammalian cells, some Hox genes show a close relationship to the apoptosis pathway.

Hox genes play crucial roles in differentiation. In HSC, the expression of Hox genes is downregulated during differentiation and maturation. The gain or loss of some Hox genes causes alterations in hematopoietic lineage commitment (He et al., 2011). Neural crest cells (NCCs) are also multipotent and can differentiate into different cell types, including peripheral and enteric neurons, glia, melanocytes, and smooth muscle. The Hox genes specify the location of the NCCs and contribute to the differentiation process (Minoux and Rijli, 2010).

Recent observations indicated that some Hox genes also have multiple functions in higher order biological mechanisms. Grooming is a stereotypic behavior in mammals and energizes the various regions of the brain, such the brainstem, striatum, and cortex. Excessive grooming manifests itself in humans as the obsessive-compulsive spectrum disorder trichtilomania. Hoxb8 knockout mice show the excessive grooming phenotype. This abnormal behavior becomes a cause of death in knockout mice (Greer and Capecchi, 2002). Cell lineage tracing showed that this aberrant behavior can be attributed to the lack of bone 
marrow-derived microglia cells (Chen et al., 2010). The reduction of the total number of microglia cells in the adult brain of Hoxb8 mutants is clear, although it remains unknown why the disruption of Hoxb8 function only affects a small fraction of microglia cells and whether Hoxb8 promotes the proliferation, differentiation or activation of apoptosis in a subpopulation of microglia cells.

These results indicate Hox genes are involved in a wide range of biological functions. However, the role of these genes in various processes is not entirely clear and knowledge of the direct targets of Hox genes is quite limited. We identified Hox protein target genes using chromatin immunopurification (ChIP) (Tomotsune et al., 1993). The use of modified methods, such as ChIP-sequence, is necessary to obtain further information on target genes and to understand their mechanisms of action.

\section{$2.2 C d x$ family}

The Hox cluster is believed to have arisen through the duplication of an ancestral ProtoHox cluster in early metazoan evolution. In this process, the ParaHox cluster genes, which show close evolutionary relationships, also arose (Garcia-Fernandez, 2005). Cdx (caudal-type homeo-box) genes are ParaHox genes, and three paralogous $C d x$ genes are present in the mouse genome and are located in different chromosomes. $C d x$ genes are required to correctly pattern the head to tail axis.

In $C d x 1^{-/-}$mutants, an anterior homeotic transformation involving the occiput and the first three cervical vertebrae is observed. These changes are accompanied by a posterior shift of Hox expression involving three different clusters (Subramanian et al., 1995).

Cdx2\% mutants present a much more severe phenotype and die between E3.5 and E5.5. The embryonic lethality of these mutants may be attributed to aberrations in the maturation of trophoblasts from the trophoectoderm. $C d x 2^{+-}$animals are viable but show tail abnormalities and growth retardation. Anterior homeotic transformation in the lower cervical and upper thoracic regions is also observed in skeletal analyses (Chawengsaksophak et al., 1997).

$C d x 4$ is an X-linked gene and no significant abnormality is observed in either sex in $C d x 4^{-/}$ embryos (van Nes et al., 2006). However, double knockout $C d x 1 \% / C d x 4 \%$ mice were

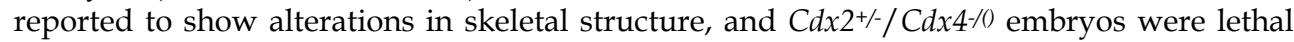
around E10.5, which was attributed to a developmental defect of the chorio-allantoic placenta.

$C d x 2^{+/-} C d x 1^{-/}$mutants show a greater degree of posterior truncation (van den Akker et al., 2002). These results indicate the existence of redundancy in the Hox clusters among the $C d x$ family genes. The $C d x$ family genes directly regulate some Hox genes, such as Hoxa5 and Hoxb8 (Subramanian et al., 1995; Tabaries et al., 2005), as these Hox genes were shown to rescue the $C d x$ mutant phenotypes (Young et al., 2009).

\subsection{Another ParaHox gene}

Hox and ParaHox genes belong to the ANTP class of homeobox genes. The ANTP class also includes two other genes, Evx (even-skipped homeotic) and Meox (mesenchyme homeobox). These two ParaHox genes, Evx and Meox, are located on either side of the Hox cluster in 
vertebrates. In the mouse genome, Evx and Meox each have two paralogous genes (Evx1, Evx2, and Meox1, Meox2) in different chromosomes. Evx1\% is characterized by early embryonic lethality as it fails to differentiate extraembryonic tissues or to form egg cylinders (Spyropoulos and Capecchi, 1994). Evx2\% mutants show malformation of the autopod, and these results indicate that Evx2 has a genetic interaction with Hoxd13 (Herault et al., 1996). Meox1/- mutants exhibit hemi-vertebrae and rib, vertebral and cranial-vertebral fusions (Jukkola et al., 2005). Meox2-/- mutants show mild defects of rib and vertebral development (Mankoo et al., 1999).

NK (Nirenberg and Kim) homeo-box genes are evolutionary relatives of both Hox and ParaHox genes. In the mouse genome, there are ten $N k x$ family genes that are located in seven different chromosomes. $N k x$ family genes are mostly observed in mesodermal derivatives; in particular, $N k x 2.5$ is essential for cardiac muscle differentiation (Hatcher et al., 2003).

\subsection{T-box family}

The T-box family genes encode a common DNA-binding domain known as the T-box and are also evolutionarily conserved transcription factors. This family of genes is composed of two independent functional domains: the T-box in the large $\mathrm{N}$-terminal region and a transcriptional activation/repression domain in the C-terminal region. The Brachyury (or T) mouse mutant is characterized by a truncated tail and was discovered about 80 years ago. Until recently, 17 genes were identified as T-box family genes in vertebrates, and genetic analyses of individual genes have progressed significantly. These analyses indicate that Tbox genes are widely involved in developmental processes of mesoderm specification (Naiche et al., 2005). In humans, mutations in T-box genes, including deletions, rearrangements, missense mutations, insertions, and truncation, lead to various genetic disorders (Packham and Brook, 2003). The phenotypes of T-box gene knockout mice can be compared with the phenotypes of several human genetic disorders.

Tbx1- mice have a lethal phenotype in late gestation and display a wide range of developmental abnormalities including facial abnormalities, cleft palate, cardiac outflow tract defects, and hypoplasia of the thymus and parathyroid glands (Jerome and Papaioannou, 2001; Merscher et al., 2001). In humans, chromosome 22q11 deletion syndrome is known as DiGeorge and velocardiofacial syndrome (DGS/VCFS) and its phenotypic characters include anomalies of the cardiac outflow tract, cleft palate, facial dysmophogenesis, and hypoplasia of the thymus and parathyroid glands. Tbx 1 is located in a region spanning $3 \mathrm{Mb}$, but another genes are also located in this region. Tbx1 is thought to be a key gene in the etiology of DES/VCFS.

Tbx3 $\%$ mice show a deficiency of mammary gland induction, genital abnormalities, and forelimb and hind limb malformations, and die during gestation(Davenport et al., 2003). However, $\mathrm{Tb} 3^{+-}$mice appear fairly unaffected. Ulnar-mammary syndrome (UMS) is a pleiotropic disease associated with malformations of the posterior elements of the upper limbs, apocrine/mammary hypoplasia and/or dysfunction, dental abnormalities, and genital anomalies. Clinical manifestations are highly variable. Many similarities are exhibited in the phenotype, but gene dose sensitivities are different between humans and mice. 
Tbx $4^{+/-m i c e}$ form hind limb buds; however, they fail to outgrow them. Tbx $4^{-/}$mutants have problems with the allantoic connection to the placenta and die early in embryogenesis (Naiche and Papaioannou, 2003). The mutations in the human Tbx4 gene are linked to an autosomal dominant disorder called small patella syndrome (SPS) (Bongers et al., 2004).

Tbx $5 \%$ resulted in early embryonic lethality due to severe defects in early heart formation (Bruneau et al., 2001). Holt-Oram syndrome is an autosomal dominant disorder that includes cardiac and upper limb malformations. Tbx $5^{+-}$mutants faithfully recapitulate the human phenotype, including cardiac defects and forelimb malformations.

As Tbx19 (known as Tpit) expression is restricted to the pituitary gland, Tbx19- mutants show a significant reduction in the number of pituitary POMC (pro-opiomelanocortin)expressing cells (Pulichino et al., 2003). In humans, the absence of pituitary POMC leads to a lack of adrenocorticotrophin (ACTH), resulting in adrenal insufficiency.

The Tbx22 $\%$ mutation caused death within $24 \mathrm{hr}$ after birth due to submucous cleft palate and ankyloglossia (Pauws et al., 2009). In humans, Tbx22 is a gene responsible for X-linked cleft palate and ankyloglossia (Braybrook et al., 2001).

\section{Developmental toxicants}

Teratology is the study of abnormal development and congenital malformations attributed to genetic factors, maternal factors, toxicants, or other factors such as environmental chemicals. In the early 1970s, James G. Wilson created "The Six Principles of Teratology". These principles are still applied today and guide the investigation of teratogenic agents and their effects on the development of organisms. A wide variety of chemicals and environmental factors are believed to have teratogenic potential in humans and animals. In the USA, the Food and Drug Administration (FDA) has categorized drugs into five different risk categories for pregnant women. These five categories $(\mathrm{A}, \mathrm{B}, \mathrm{C}, \mathrm{D}$, and $\mathrm{X}$ ) have been considered a therapeutic advantage but they are only based on specific criteria and are not universal. Therefore, the number of these factors is likely higher than one thousand and is increasing daily. The teratogenic potentials of various chemicals and environmental factors are determined using animal models (e.g., zebra fish, mouse, rat, pig, rabbit, dog, and monkey). In the past, observations of the characteristics of embryos from candidate-exposed pregnant animals were used as the main criteria, but current teratological evaluations need to include knowledge about the molecular mechanisms.

In this section, six xenobiotics known to be developmental toxicants in humans were selected for further description.

\subsection{Endocrine disruptors}

Under normal conditions, hormones are involved in the maintenance of homeostasis, but endocrine disruptors, which are environmental chemicals that have a hormone action or inhibit the activity of an endogenous hormone, have an adverse effect on organs and progeny. In adults, the role of the endocrine system in the maintenance of homeostasis is established and adults therefore have resistance against endocrine disruptors. However, in the fetus, infants, and children, resistance against these agents may be weak and they therefore can have irreversible impact on developmental functions such as organ formation. 
Endocrine disruptors are found in low doses in products of daily use. DTT, polychlorinated biphenyls (PCBs), bisphenol A (BPA), polybrominated diphenyl esters (PBDEs), and a variety of phthalates are chemicals used in pesticides, plastic food containers or plastic toys, and are currently recognized as endocrine disruptors.

Methoxychlor (MXC) is an organochlorine DDT derivative. MXC was shown to affect fertility in mice and cause maternal weight gain in fetal rats. These effects are thought to be mediated by the inhibition of estrogen binding to the Estrogen Receptor (Esr), by MXC and the suppression of the expression of Hoxa10 (Fei et al., 2005).

BPA also affects estrogen signaling. In BPA-exposed males, an increase in the size of the prostate gland and oligospermia are observed. BPA exposure negatively regulates the expression of Hoxa10 and Hoxa11 and affects estrogen signaling (Varayoud et al., 2008).

Estrogen and androgen are sex steroids that are needed for the proper development of reproductive organs (Dupont et al., 2000). Each steroid binds to a specific nuclear-receptor and these receptors act as ligand-dependent transcription factors. Alterations in Hox gene expression induced by endocrine disruptors is thus considered to be a nuclear receptormediated mechanism.

\subsection{Diethylstilbestrol (DES)}

DES is a synthetic nonsteroidal estrogen. This chemical was used as a pharmaceutical product for the prevention of miscarriage in the 1970s, but vaginal cancer occurred frequently in children whose mothers took DES. Exposed offspring also experienced a high incidence of pregnancy wastage and preterm labor. DES induced altered Hox gene expression in human uterine endometrial and cervical cells. In reproductive organs, Hox genes are also expressed along the A-P axis. Under this rule, Hoxa9 is normally expressed in the oviduct and Hoxa10 in the uterus. However, this linear regulation of expression is disrupted in DES-exposed humans or mice, and the expressional domain is shifted posteriorly (Block et al., 2000). DES binds the Esr, and the irregular nuclear receptor activation may lead to aberrant Hox gene expression.

\subsection{Anticonvulsants (VPA)}

Valoproic acid (VPA) is a chemical compound used for the treatment of epilepsy. However, VPA has teratogenic potential along with other anticonvulsant drugs, including carbamazepine and phenytoin in humans. Having weak developmental toxicant of carbamazepine and phenytoin, VPA exposure is more toxicant. In humans, infants exposed to VPA in utero show anomalies including neural, craniofacial, cardiovascular, and skeletal defects. A similar teratology is exhibited in rodents, rabbits, and nonhuman primates. The spina bifida, a neural tube defect, is also observed in VPA-exposed infants at frequencies of 1-2\%. VPA exposed human embryonic carcinoma (NTera2/D1) cells show slight alterations in the expression of certain Hox genes (Faiella et al., 2000). VPA is also an inhibitor of class I and IIa HDACs (histone deacetylases); therefore, changes in the expressions of various genes are thought to occur in different tissues. However, it remains largely unknown why phenotypes appear only in limited organs in which HDAC is the primary target of VPA, and the mechanisms underlying the action of VPA are not clear. 


\subsection{Thalidomide}

Thalidomide ( $\mathrm{a}$-phthaliidoglutarimide) was used as a sedative and for morning sickness in the late 1950s. However, reports of the teratogenic potency of thalidomide appeared in the early 1960s. In these reports, infants exposed to thalidomide during the early stages of pregnancy had multiple defects, such as malformations of the limbs, ears, eyes, internal organs and central nervous system. The most commonly observed defects were limb malformations including amelia (complete absence of the limb) and phocomelia (truncation or absence of the zeugopod). Thalidomide-induced limb defects are observed in humans, monkeys, rabbits and chicks, but these phenotypes are not observed in the mouse or rat (Vargesson, 2009). For 50 years, the mechanism of thalidomide-teratogenicity was poorly understood. Thalidomide is a derivative of glutamic acid and contains two imide rings: glutarimide and phthalimide. Thalidomide has therefore been believed to act by causing biochemical alterations of glutamic acid, nucleic acids and vitamin B. Recently, the primary target of thalidomide was identified and parts of the molecular mechanism were revealed (Ito et al., 2010). A thalidomide-binding protein, Cereblon (CRBN), forms an E3 ubiquitin ligase complex with Ddb1 and Cul4A in a thalidomide-dependent manner and modifies the expression of $F g f 8$ in the limb. Generally, the limb has three developmental axes: the proximal-distal axis, which runs from the base of the limb to the tip; the A-P axis, which runs parallel with the body axis; and the D-V axis, which runs from the back of the hand to the palm. Under the control of these three axes, various positional identities are specified by the concentration gradient of diffusible factors, such as Fgfs, Bmps, Wht, and Sonic Hedgehog. The malformed fin or limb in knockdown Crbn zebrafish or the dominant negative form of Crbn expressing chicken, respectively, indicated the important role of the ubiquitin ligase pathway for morphogenesis through thalidomide, and clearly showed that the reduction of Fgf8 expression lead to the deformity of the limb. Although there is no information about the specific target molecule of Crbn, identification of this target molecule will allow a more effective use of thalidomide for the treatment of multiple myeloma and erythema nodosum leprosum and avoid its associated teratogenic risks.

\subsection{Retinoic acid}

In normal embryogenesis, a wide variety of diffusible factors act as morphogens and control proper morphogenesis. Retinoic acid is one of the morphogens that function during the formation of various organs such as the head, trunk, limbs, heart, and the central nervous system. Retinol and other retinoid compounds, which are precursors of retinoic acid, cannot be synthesized de novo and must therefore be ingested in food or supplements. After modification of ingested retinol by multiple enzymes, the resulting compounds bind to ligand-activated nuclear receptors, namely Rar (retinoic acid receptor) and Rxr (retinoid X receptor). Rar and Rxr are concurrently encoded by three family genes ( $a, \beta$, and $\gamma$ ), and subtypes exist that are products of alternative splicing or different promoter usage. The activated nuclear receptors form homo- or hetero-dimers and recruit coactivators or corepressors to the RARE (retinoic acid response element) on the target genes. Some target genes have been identified and these genes function in the cell cycle, proliferation, and morphogenesis (Delacroix et al., 2010; Nielsen et al., 2008).

Retinoids were found to be teratogenic in humans in the early 1980s. Infants exposed during gestation have teratogenic syndrome including craniofacial abnormalities and defects of the 
thymic, cardiovascular, and central nervous system. The teratogenic effect is observed in other animal models, such as mouse, rat, pig, rabbit, dog, chick, and monkey. The dosage and timing of gestational exposure profoundly influence the form of the birth defect and the lethality, but differences in the genetic background in mice also have an effect. The peak period of sensitivity for a given tissue appears to be during the development of the primordial structures.

Rar and Rxr knockout mice were produced by several methods and these mice exhibited various phenotypes (Mark et al., 2006). However, their abnormalities were restricted to a subset of tissues normally expressing these receptors, probably reflecting the existence of functional redundancies between nuclear receptors. The expression of certain Hox genes is controlled via RARE (Oosterveen et al., 2003). Although differences in the RA exposure dosage determine the phenotypes, aberrant Hox gene expression is thought to play a role in the morphological malformations.

\subsection{Dioxin}

PCDDs (polychlorinated dibenzo-p-dioxins), PCDFs (polychlorinated dibenzofurans) and DL-PCBs (dioxin-like polychlorinated biphenyls) are generically termed as dioxin and are similar toxicants. Dioxin is an environmental contaminant and is unintentionally generated as a by-product of industrial combustion. Among dioxins, $\operatorname{TCDD}(2,3,7,8$-Tetrachlorodibenzo-pdioxin) is the most severe toxicant and has the highest teratogenic potency in mammals. Differences in the exposure dosage determine the resulting phenotypes, which include cleft palate, hydronephrosis, and defects of sex organs. There are differences due to timing and dose of exposure, TCDD exposure causes a significant decrease in ventral prostate development, which is similar to the effect of impairment of certain Hox genes (Vezina et al., 2009), but the correlativity between TCDD and Hox expression is not cleared.

The molecular mechanisms of the xenobiotic dioxin pathway can be understood through the analyses of nuclear receptors. The toxicant and teratogenic effects of dioxin are thought to depend on the activation of the Ahr (aryl hydorocarbon receptor) pathway. Ahr has multiple functions. Ahr is a ligand-activated transcription factor that is a member of the bHLH/PAS (basic Helix-loop-Helix/Per-Arnt-Sim) family of genes. Ahr generally localizes to the cytoplasm and forms a complex with Hsp90 (heat shock protein 90), cochaperone p23, and the immunophilin-like protein Ara9 (Bell and Poland, 2000). Upon binding ligand, Ahr is released from the p23/Ara9 complex and translocates to the nucleus. In the nucleus, Ahr dissociates from Hsp90 and dimerizes with another bHLH-PAS family gene, Arnt (Ahr nuclear translocator). The Ahr/Arnt heterodimer binds to specific DNA sequences termed XREs (xenobiotic response elements: 5'-GCGTG-3') and regulates target gene expression with transcriptional coactivators/corepressors, which are also partners of Rar/Rxr (Beischlag et al., 2002). Currently, various genes are reported as Ahr target genes: phase I drug metabolizing enzymes, such as those of the Cyp450 (Cytochorome 450) family; phase II enzymes, such as Ugt1a1 (Kohle and Bock, 2007); and as down stream genes of Ahrpathway, such as cytokines, and $T g f$ family which are unrelated xenobiotic metabolism genes (Haarmann-Stemmann et al., 2009).

Ahr is also a modulator of estrogen receptor signaling. Ohtake et al. indicated that the ligand-activated Ahr/Arnt heterodimer directly associates with the Esr, recruits a coactivator, and regulates the expression of Esr target genes (Ohtake et al., 2003). In this 
case, Ahr functions as activator/repressor depending on the ligand binding state of the Esr. Another function of ligand-activated $\mathrm{Ahr}$ as a substrate-specific adaptor in the Cullin $4 \mathrm{~B}$ ubiquitin ligase complex was described (Ohtake et al., 2007). In this case, agonist (3MC: 3methylcholanthrene)-activated Ahr ubiquitinates Esr1 and androgen receptor (Ar) in vitro and in vivo. In Ahr-deficient mice, responses to dioxin such as the induction of Cyp1a1 activation were not observed. However, null mutants have functional impairments of male and female reproductive organs, depending on the affected allele (Schmidt et al., 1996). Although there are other identified ligands for Ahr, including flavonoids, UV photoproducts of tryptophan and some synthetic retinoids, the above observations suggest that Ahr plays a role in the cross talk between the dioxin and RA pathways.

\section{Hox-RA/dioxin}

The identification of molecular markers for the variety of existing teratogenic factors is an urgent need in various respects. In the present report, we focused on the expressional changes of the Hox cluster genes in embryos exposed to teratogenic factors because their aberrant expression lead to various morphological defects and the affected animals have close similarities (Kojima and Takahashi, 2009).

Because the different amount and timing of exposure to teratogenic factors are correlated to the different effects in embryos, we firstly examined the RA or dioxin effects in E10.5 embryos for $6 \mathrm{hr}$ by one-shot administration. This dose induced craniofacial and skeletal defects in RA-exposed embryos, and hydronephrosis in dioxin-exposed embryos. Among 39 Hox cluster genes, 3'-located paralogs $(H o x 1 \sim 8)$ were up-regulated and some 5 '-located genes (Hoxa11, Hoxd9, and Hoxd12) were down-regulated in the RA-exposed embryos (Fig. 1). Meanwhile, the influence of relative position in the cluster was not observed in the TCDD-exposed embryos. A and D cluster genes were down-regulated and no clear difference was observed in the cluster B. Additionally, aberrant expression of pri-miRNAs (precursors of miRNAs) was detected (Fig. 2). These pri-miRNA changes were correlated with changes in the expression of closely located Hox genes.

TCDD exposure causes a decrease in the levels of all-trans RA in the liver, which is the main RA storage location in a variety of species (Fletcher et al., 2001). There are some similarities in terms of morphological changes between RA- and TCDD-exposed embryos. The developmental effects of the replacement of RA storage by TCDD are not clear, but it is suggested that TCDD and related compounds have an impact on retinoid homeostasis and the RA signaling pathway. Our analyses indicate that alterations in the expression of Hox cluster genes do not show a clear correlation with these teratogenic factors. In addition, expressional changes of some pri-miRNAs in the Hox clusters are also different between these two factors. Although the involvement of Ahr in the cross talk between the RA and TCDD pathways is possible, there are clear differences in the downstream effects, such as expressional changes of Hox cluster genes. We also detected changes in the expression of other transcription factors, such as ParaHoxs and T-box family genes, in embryos exposed to these factors. Some genes show a specific response to each teratogenic factor. Based on these results, changes in the expression of transcription factors can be considered as potential molecular markers for the verification of teratogenic effects. Therefore, to better determine the teratogenic potential of various chemicals, further investigation of the effects of the timing or dosage of RA and TCDD in exposed embryos is under way. 


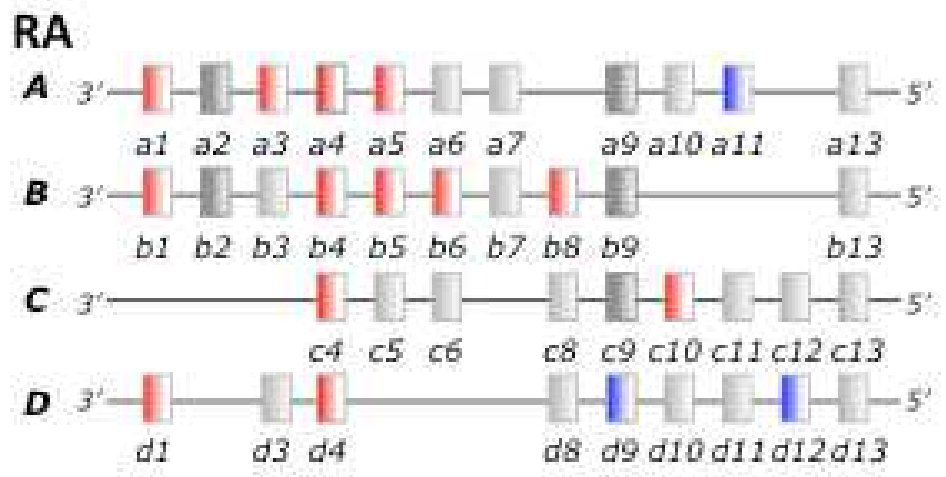

\section{TCDD}

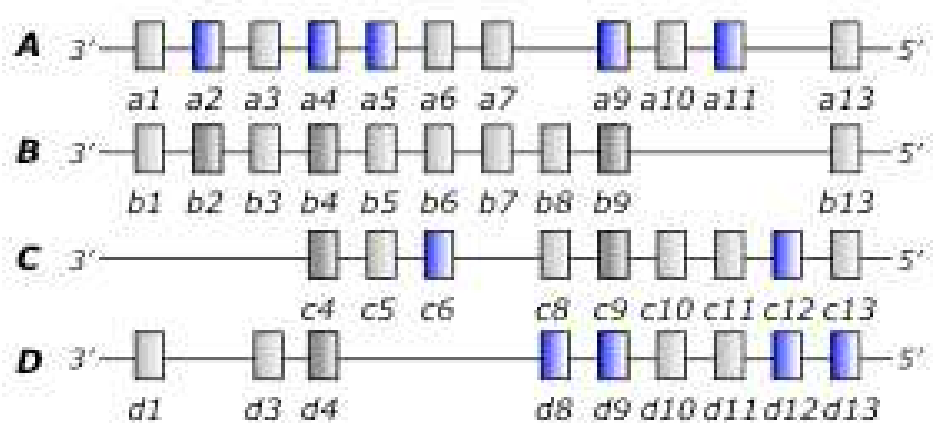

Fig. 1. Expressional changes of the Hox cluster genes in embryos treated with teratogenic agents. 39 Hox genes are separated on four clusters (A, B, C, and D) in four chromosomal loci. The box indicates each gene. Red boxes indicate up-regulated and blue boxes indicate down-regulated genes in response to treatment with teratogenic agents.

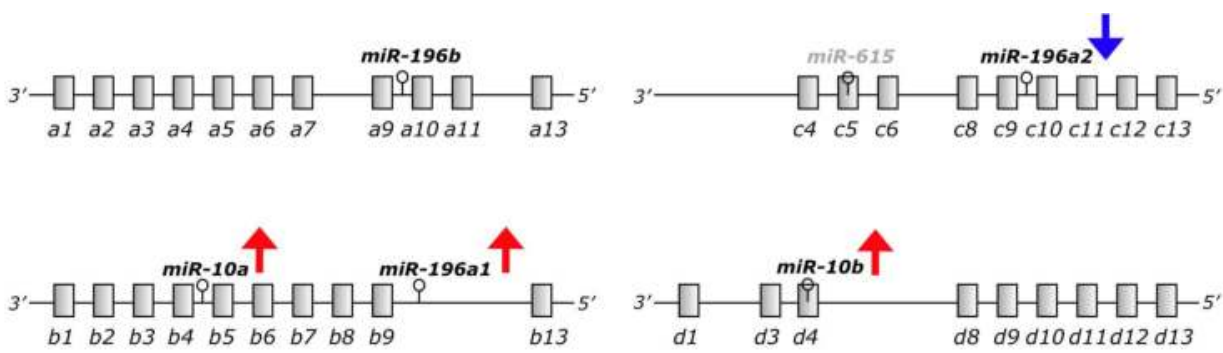

Fig. 2. Expressional changes of pri-miRNAs in the Hox cluster genes. Three miRNA family genes (miR-196, miR-10, and miR-615) are located in the Hox cluster. Red arrows indicate RA and the blue arrow indicates TCDD exposure. The upward direction of the arrow represents increased expression and the downward direction represents decreased expression. 


\section{Conclusions}

Contrasting a comprehensive analysis using DNA microarrays, our analysis is simpler and allows the examination of a large number of samples. Information on molecular markers such as the Hox genes under various conditions (exposure-time, -dosage) will allow the prediction of the hazardous nature of unknown factors. In addition, the understanding of the molecular mechanisms common to different teratogenic agents requires the identification of the target genes of Hox protein and each transcription factor and an understanding of transcription factor networks.

\section{References}

Antonchuk, J., Sauvageau, G., and Humphries, R.K. (2002). HOXB4-induced expansion of adult hematopoietic stem cells ex vivo. Cell 109, 39-45.

Augui, S., Nora, E.P., and Heard, E. (2011). Regulation of X-chromosome inactivation by the X-inactivation centre. Nat Rev Genet 12, 429-442.

Balling, R., Mutter, G., Gruss, P., and Kessel, M. (1989). Craniofacial abnormalities induced by ectopic expression of the homeobox gene Hox-1.1 in transgenic mice. Cell 58, 337-347.

Beischlag, T.V., Wang, S., Rose, D.W., Torchia, J., Reisz-Porszasz, S., Muhammad, K., Nelson, W.E., Probst, M.R., Rosenfeld, M.G., and Hankinson, O. (2002). Recruitment of the NCoA/SRC-1/p160 family of transcriptional coactivators by the aryl hydrocarbon receptor/aryl hydrocarbon receptor nuclear translocator complex. Mol.Cell.Biol. 22, 4319-4333.

Bell, D.R., and Poland, A. (2000). Binding of aryl hydrocarbon receptor (AhR) to AhRinteracting protein. The role of hsp90. J Biol Chem 275, 36407-36414.

Bernstein, B.E., Mikkelsen, T.S., Xie, X., Kamal, M., Huebert, D.J., Cuff, J., Fry, B., Meissner, A., Wernig, M., Plath, K., et al. (2006). A bivalent chromatin structure marks key developmental genes in embryonic stem cells. Cell 125, 315-326.

Bjornsson, J.M., Larsson, N., Brun, A.C., Magnusson, M., Andersson, E., Lundstrom, P., Larsson, J., Repetowska, E., Ehinger, M., Humphries, R.K., et al. (2003). Reduced proliferative capacity of hematopoietic stem cells deficient in Hoxb3 and Hoxb4. Mol.Cell.Biol. 23, 3872-3883.

Block, K., Kardana, A., Igarashi, P., and Taylor, H.S. (2000). In utero diethylstilbestrol (DES) exposure alters Hox gene expression in the developing mullerian system. Faseb J14, 1101-1108.

Bongers, E.M., Duijf, P.H., van Beersum, S.E., Schoots, J., Van Kampen, A., Burckhardt, A., Hamel, B.C., Losan, F., Hoefsloot, L.H., Yntema, H.G., et al. (2004). Mutations in the human TBX4 gene cause small patella syndrome. Am. J. Hum. Genet. 74, 1239-1248.

Braybrook, C., Doudney, K., Marcano, A.C., Arnason, A., Bjornsson, A., Patton, M.A., Goodfellow, P.J., Moore, G.E., and Stanier, P. (2001). The T-box transcription factor gene TBX22 is mutated in X-linked cleft palate and ankyloglossia. Nat Genet 29, 179183.

Bruneau, B.G., Nemer, G., Schmitt, J.P., Charron, F., Robitaille, L., Caron, S., Conner, D.A., Gessler, M., Nemer, M., Seidman, C.E., et al. (2001). A murine model of Holt-Oram syndrome defines roles of the T-box transcription factor Tbx 5 in cardiogenesis and disease. Cell 106, 709-721.

Chawengsaksophak, K., James, R., Hammond, V.E., Kontgen, F., and Beck, F. (1997). Homeosis and intestinal tumours in Cdx2 mutant mice. Nature 386, 84-87. 
Chen, H., Chung, S., and Sukumar, S. (2004). HOXA5-induced apoptosis in breast cancer cells is mediated by caspases 2 and 8. Mol. Cell. Biol. 24, 924-935.

Chen, S.K., Tvrdik, P., Peden, E., Cho, S., Wu, S., Spangrude, G., and Capecchi, M.R. (2010). Hematopoietic origin of pathological grooming in Hoxb8 mutant mice. Cell 141, 775-785.

Davenport, T.G., Jerome-Majewska, L.A., and Papaioannou, V.E. (2003). Mammary gland, limb and yolk sac defects in mice lacking Tbx3, the gene mutated in human ulnar mammary syndrome. Development 130, 2263-2273.

Delacroix, L., Moutier, E., Altobelli, G., Legras, S., Poch, O., Choukrallah, M.A., Bertin, I., Jost, B., and Davidson, I. (2010). Cell-specific interaction of retinoic acid receptors with target genes in mouse embryonic fibroblasts and embryonic stem cells. Mol.Cell.Biol. 30, 231-244.

Di-Poi, N., Zakany, J., and Duboule, D. (2007). Distinct roles and regulations for HoxD genes in metanephric kidney development. PLoS Genet 3, e232.

Dolle, P., Dierich, A., LeMeur, M., Schimmang, T., Schuhbaur, B., Chambon, P., and Duboule, D. (1993). Disruption of the Hoxd-13 gene induces localized heterochrony leading to mice with neotenic limbs. Cell 75, 431-441.

Dupont, S., Krust, A., Gansmuller, A., Dierich, A., Chambon, P., and Mark, M. (2000). Effect of single and compound knockouts of estrogen receptors alpha (ERalpha) and beta (ERbeta) on mouse reproductive phenotypes. Development 127, 4277-4291.

Economides, K.D., and Capecchi, M.R. (2003). Hoxb13 is required for normal differentiation and secretory function of the ventral prostate. Development 130, 2061-2069.

Faiella, A., Wernig, M., Consalez, G.G., Hostick, U., Hofmann, C., Hustert, E., Boncinelli, E., Balling, R., and Nadeau, J.H. (2000). A mouse model for valproate teratogenicity: parental effects, homeotic transformations, and altered HOX expression. Hum. Mol. Genet. 9, 227-236.

Fei, X., Chung, H., and Taylor, H.S. (2005). Methoxychlor disrupts uterine Hoxa10 gene expression. Endocrinology 146, 3445-3451.

Fletcher, N., Hanberg, A., and Hakansson, H. (2001). Hepatic vitamin a depletion is a sensitive marker of 2,3,7,8-tetrachlorodibenzo-p-dioxin (TCDD) exposure in four rodent species. Toxicol Sci 62, 166-175.

Fromental-Ramain, C., Warot, X., Messadecq, N., LeMeur, M., Dolle, P., and Chambon, P. (1996). Hoxa-13 and Hoxd-13 play a crucial role in the patterning of the limb autopod. Development 122, 2997-3011.

Garcia-Fernandez, J. (2005). The genesis and evolution of homeobox gene clusters. Nat Rev Genet 6, 881-892.

Gendron-Maguire, M., Mallo, M., Zhang, M., and Gridley, T. (1993). Hoxa-2 mutant mice exhibit homeotic transformation of skeletal elements derived from cranial neural crest. Cell 75, 1317-1331.

Goodman, F.R. (2002). Limb malformations and the human HOX genes. Am. J. Med. Genet. $112,256-265$.

Greer, J.M., and Capecchi, M.R. (2002). Hoxb8 is required for normal grooming behavior in mice. Neuron 33, 23-34.

Haarmann-Stemmann, T., Bothe, H., and Abel, J. (2009). Growth factors, cytokines and their receptors as downstream targets of arylhydrocarbon receptor (AhR) signaling pathways. Biochem Pharmacol 77, 508-520.

Hatcher, C.J., Diman, N.Y., McDermott, D.A., and Basson, C.T. (2003). Transcription factor cascades in congenital heart malformation. Trends. Mol. Med. 9, 512-515. 
He, H., Hua, X., and Yan, J. (2011). Epigenetic regulations in hematopoietic Hox code. Oncogene 30, 379-388.

Herault, Y., Hraba-Renevey, S., van der Hoeven, F., and Duboule, D. (1996). Function of the Evx-2 gene in the morphogenesis of vertebrate limbs. EMBO J 15, 6727-6738.

Hornstein, E., Mansfield, J.H., Yekta, S., Hu, J.K., Harfe, B.D., McManus, M.T., Baskerville, S., Bartel, D.P., and Tabin, C.J. (2005). The microRNA miR-196 acts upstream of Hoxb8 and Shh in limb development. Nature 438, 671-674.

Hughes, C.L., and Kaufman, T.C. (2002). Hox genes and the evolution of the arthropod body plan. Evol Dev 4, 459-499.

Ito, T., Ando, H., Suzuki, T., Ogura, T., Hotta, K., Imamura, Y., Yamaguchi, Y., and Handa, H. (2010). Identification of a primary target of thalidomide teratogenicity. Science 327, 1345-1350.

Jerome, L.A., and Papaioannou, V.E. (2001). DiGeorge syndrome phenotype in mice mutant for the T-box gene, Tbx1. Nat Genet 27, 286-291.

Jukkola, T., Trokovic, R., Maj, P., Lamberg, A., Mankoo, B., Pachnis, V., Savilahti, H., and Partanen, J. (2005). Meox1Cre: a mouse line expressing Cre recombinase in somitic mesoderm. Genesis 43, 148-153.

Kohle, C., and Bock, K.W. (2007). Coordinate regulation of Phase I and II xenobiotic metabolisms by the Ah receptor and Nrf2. Biochem Pharmacol 73, 1853-1862.

Kojima, T., and Takahashi, N. (2009). Influence of teratogenic factors on mouse 39 hox gene expression. Biosci. Biotechnol. Biochem. 73, 2416-2421.

Kyba, M., Perlingeiro, R.C., and Daley, G.Q. (2002). HoxB4 confers definitive lymphoidmyeloid engraftment potential on embryonic stem cell and yolk sac hematopoietic progenitors. Cell 109, 29-37.

Lohmann, I., McGinnis, N., Bodmer, M., and McGinnis, W. (2002). The Drosophila Hox gene deformed sculpts head morphology via direct regulation of the apoptosis activator reaper. Cell 110, 457-466.

Malik, S., and Grzeschik, K.H. (2008). Synpolydactyly: clinical and molecular advances. Clin Genet 73, 113-120.

Mallo, M., Wellik, D.M., and Deschamps, J. (2010). Hox genes and regional patterning of the vertebrate body plan. Dev Biol 344, 7-15.

Mankoo, B.S., Collins, N.S., Ashby, P., Grigorieva, E., Pevny, L.H., Candia, A., Wright, C.V., Rigby, P.W., and Pachnis, V. (1999). Mox2 is a component of the genetic hierarchy controlling limb muscle development. Nature 400, 69-73.

Mansfield, J.H., Harfe, B.D., Nissen, R., Obenauer, J., Srineel, J., Chaudhuri, A., FarzanKashani, R., Zuker, M., Pasquinelli, A.E., Ruvkun, G., et al. (2004). MicroRNAresponsive 'sensor' transgenes uncover Hox-like and other developmentally regulated patterns of vertebrate microRNA expression. Nat Genet 36, 1079-1083.

Mark, M., Ghyselinck, N.B., and Chambon, P. (2006). Function of retinoid nuclear receptors: lessons from genetic and pharmacological dissections of the retinoic acid signaling pathway during mouse embryogenesis. Annu. Rev. Pharmacol. Toxicol. 46, 451-480.

McLain, K., Schreiner, C., Yager, K.L., Stock, J.L., and Potter, S.S. (1992). Ectopic expression of Hox-2.3 induces craniofacial and skeletal malformations in transgenic mice. Mech Dev 39, 3-16.

Mendenhall, E.M., and Bernstein, B.E. (2008). Chromatin state maps: new technologies, new insights. Curr. Opin. Genet. Dev. 18, 109-115.

Merscher, S., Funke, B., Epstein, J.A., Heyer, J., Puech, A., Lu, M.M., Xavier, R.J., Demay, M.B., Russell, R.G., Factor, S., et al. (2001). TBX1 is responsible for cardiovascular defects in velo-cardio-facial/DiGeorge syndrome. Cell 104, 619-629. 
Minoux, M., and Rijli, F.M. (2010). Molecular mechanisms of cranial neural crest cell migration and patterning in craniofacial development. Development 137, 2605-2621.

Moens, C.B., and Selleri, L. (2006). Hox cofactors in vertebrate development. Dev Biol 291, 193-206.

Moore, M.A., Chung, K.Y., Plasilova, M., Schuringa, J.J., Shieh, J.H., Zhou, P., and Morrone, G. (2007). NUP98 dysregulation in myeloid leukemogenesis. Ann. N. Y. Acad. Sci. $1106,114-142$.

Naiche, L.A., Harrelson, Z., Kelly, R.G., and Papaioannou, V.E. (2005). T-box genes in vertebrate development. Annu Rev Genet 39, 219-239.

Naiche, L.A., and Papaioannou, V.E. (2003). Loss of Tbx4 blocks hindlimb development and affects vascularization and fusion of the allantois. Development 130, 2681-2693.

Nielsen, R., Pedersen, T.A., Hagenbeek, D., Moulos, P., Siersbaek, R., Megens, E., Denissov, S., Borgesen, M., Francoijs, K.J., Mandrup, S., et al. (2008). Genome-wide profiling of PPARgamma:RXR and RNA polymerase II occupancy reveals temporal activation of distinct metabolic pathways and changes in RXR dimer composition during adipogenesis. Genes Dev 22, 2953-2967.

Ohtake, F., Baba, A., Takada, I., Okada, M., Iwasaki, K., Miki, H., Takahashi, S., Kouzmenko, A., Nohara, K., Chiba, T., et al. (2007). Dioxin receptor is a ligand-dependent E3 ubiquitin ligase. Nature 446, 562-566.

Ohtake, F., Takeyama, K., Matsumoto, T., Kitagawa, H., Yamamoto, Y., Nohara, K., Tohyama, C., Krust, A., Mimura, J., Chambon, P., et al. (2003). Modulation of oestrogen receptor signalling by association with the activated dioxin receptor. Nature $423,545-550$.

Oosterveen, T., Niederreither, K., Dolle, P., Chambon, P., Meijlink, F., and Deschamps, J. (2003). Retinoids regulate the anterior expression boundaries of $5^{\prime}$ Hoxb genes in posterior hindbrain. EMBO J 22, 262-269.

Packham, E.A., and Brook, J.D. (2003). T-box genes in human disorders. Hum. Mol. Genet. 12 Spec No 1, R37-44.

Pauws, E., Hoshino, A., Bentley, L., Prajapati, S., Keller, C., Hammond, P., Martinez-Barbera, J.P., Moore, G.E., and Stanier, P. (2009). Tbx22null mice have a submucous cleft palate due to reduced palatal bone formation and also display ankyloglossia and choanal atresia phenotypes. Hum. Mol. Genet. 18, 4171-4179.

Podlasek, C.A., Clemens, J.Q., and Bushman, W. (1999). Hoxa-13 gene mutation results in abnormal seminal vesicle and prostate development. J Urol 161, 1655-1661.

Podlasek, C.A., Duboule, D., and Bushman, W. (1997). Male accessory sex organ morphogenesis is altered by loss of function of Hoxd-13. Dev Dyn 208, 454-465.

Pulichino, A.M., Vallette-Kasic, S., Tsai, J.P., Couture, C., Gauthier, Y., and Drouin, J. (2003). Tpit determines alternate fates during pituitary cell differentiation. Genes Dev 17, 738-747.

Raman, V., Martensen, S.A., Reisman, D., Evron, E., Odenwald, W.F., Jaffee, E., Marks, J., and Sukumar, S. (2000). Compromised HOXA5 function can limit p53 expression in human breast tumours. Nature 405, 974-978.

Rinn, J.L., Kertesz, M., Wang, J.K., Squazzo, S.L., Xu, X., Brugmann, S.A., Goodnough, L.H., Helms, J.A., Farnham, P.J., Segal, E., et al. (2007). Functional demarcation of active and silent chromatin domains in human HOX loci by noncoding RNAs. Cell 129, 1311-1323. 
Sauvageau, G., Thorsteinsdottir, U., Eaves, C.J., Lawrence, H.J., Largman, C., Lansdorp, P.M., and Humphries, R.K. (1995). Overexpression of HOXB4 in hematopoietic cells causes the selective expansion of more primitive populations in vitro and in vivo. Genes Dev 9, 1753-1765.

Schmidt, J.V., Su, G.H., Reddy, J.K., Simon, M.C., and Bradfield, C.A. (1996). Characterization of a murine Ahr null allele: involvement of the Ah receptor in hepatic growth and development. Proc. Natl. Acad. Sci. USA 93, 6731-6736.

Shah, N., and Sukumar, S. (2010). The Hox genes and their roles in oncogenesis. Nat Rev Cancer 10, 361-371.

Spyropoulos, D.D., and Capecchi, M.R. (1994). Targeted disruption of the even-skipped gene, evx1, causes early postimplantation lethality of the mouse conceptus. Genes Dev 8, 1949-1961.

Subramanian, V., Meyer, B.I., and Gruss, P. (1995). Disruption of the murine homeobox gene $\mathrm{Cdx1}$ affects axial skeletal identities by altering the mesodermal expression domains of Hox genes. Cell 83, 641-653.

Tabaries, S., Lapointe, J., Besch, T., Carter, M., Woollard, J., Tuggle, C.K., and Jeannotte, L. (2005). Cdx protein interaction with Hoxa5 regulatory sequences contributes to Hoxa5 regional expression along the axial skeleton. Mol.Cell.Biol. 25, 1389-1401.

Tomotsune, D., Shoji, H., Wakamatsu, Y., Kondoh, H., and Takahashi, N. (1993). A mouse homologue of the Drosophila tumour-suppressor gene 1(2)gl controlled by Hox-C8 in vivo. Nature $365,69-72$.

van den Akker, E., Forlani, S., Chawengsaksophak, K., de Graaff, W., Beck, F., Meyer, B.I., and Deschamps, J. (2002). Cdx1 and Cdx2 have overlapping functions in anteroposterior patterning and posterior axis elongation. Development 129, 2181-2193.

van Nes, J., de Graaff, W., Lebrin, F., Gerhard, M., Beck, F., and Deschamps, J. (2006). The $\mathrm{Cd} \times 4$ mutation affects axial development and reveals an essential role of $\mathrm{Cdx}$ genes in the ontogenesis of the placental labyrinth in mice. Development 133, 419-428.

Varayoud, J., Ramos, J.G., Bosquiazzo, V.L., Munoz-de-Toro, M., and Luque, E.H. (2008). Developmental exposure to Bisphenol a impairs the uterine response to ovarian steroids in the adult. Endocrinology 149, 5848-5860.

Vargesson, N. (2009). Thalidomide-induced limb defects: resolving a 50-year-old puzzle. Bioessays 31, 1327-1336.

Vezina, C.M., Lin, T.M., and Peterson, R.E. (2009). AHR signaling in prostate growth, morphogenesis, and disease. Biochem Pharmacol 77, 566-576.

Wang, K.C., Yang, Y.W., Liu, B., Sanyal, A., Corces-Zimmerman, R., Chen, Y., Lajoie, B.R., Protacio, A., Flynn, R.A., Gupta, R.A., et al. (2011). A long noncoding RNA maintains active chromatin to coordinate homeotic gene expression. Nature 472, 120-124.

Warot, X., Fromental-Ramain, C., Fraulob, V., Chambon, P., and Dolle, P. (1997). Gene dosage-dependent effects of the Hoxa-13 and Hoxd-13 mutations on morphogenesis of the terminal parts of the digestive and urogenital tracts. Development 124, 4781-4791.

Wellik, D.M. (2009). Hox genes and vertebrate axial pattern. Curr. Top. Dev. Biol. 88, 257-278.

Wellik, D.M., Hawkes, P.J., and Capecchi, M.R. (2002). Hox11 paralogous genes are essential for metanephric kidney induction. Genes Dev 16, 1423-1432.

Yekta, S., Shih, I.H., and Bartel, D.P. (2004). MicroRNA-directed cleavage of HOXB8 mRNA. Science 304, 594-596.

Young, T., Rowland, J.E., van de Ven, C., Bialecka, M., Novoa, A., Carapuco, M., van Nes, J., de Graaff, W., Duluc, I., Freund, J.N., et al. (2009). Cdx and Hox genes differentially regulate posterior axial growth in mammalian embryos. Dev Cell 17, 516-526. 


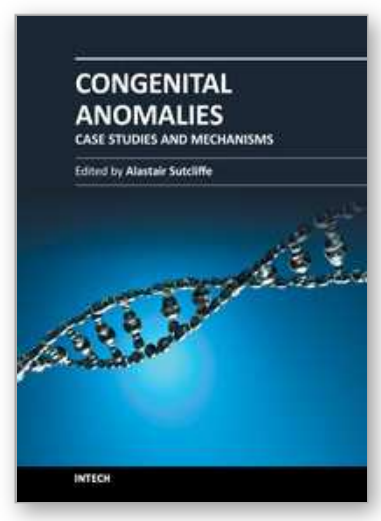

\author{
Congenital Anomalies - Case Studies and Mechanisms \\ Edited by Dr. Alastair Sutcliffe
}

ISBN 978-953-51-0075-1

Hard cover, 132 pages

Publisher InTech

Published online 22, February, 2012

Published in print edition February, 2012

This book is in essence a collection of essays which are state of the art in their respective areas of knowledge. They inform the reader of all sorts of mechanistic considerations when developing understanding of issues surrounding the origins of congenital abnormalities. These chapters are written by world renown authorities in this area of science and represent a wide range of expertise from a clinician perspective, through to genetic mechanisms. Unlike some books which take a formal textual, somewhat plodding way through pathophysiology here instead we have cut through chapters in which the student, or scientist or medic is lead to understand just how complex the origins can be via examples from different parts of the body. With the erudite chapters are relevant tables and other diagrams to help clarify the text. These chapters represent a starter text for the stimulus for further knowledge of what is an increasingly important area of human health.

\title{
How to reference
}

In order to correctly reference this scholarly work, feel free to copy and paste the following:

Takuya Kojima and Naoki Takahashi (2012). Hox Genes and Teratogenic Factors, Congenital Anomalies Case Studies and Mechanisms, Dr. Alastair Sutcliffe (Ed.), ISBN: 978-953-51-0075-1, InTech, Available from: http://www.intechopen.com/books/congenital-anomalies-case-studies-and-mechanisms/hox-genes-andteratogenic-factors

\section{INTECH}

open science | open minds

\author{
InTech Europe \\ University Campus STeP Ri \\ Slavka Krautzeka 83/A \\ 51000 Rijeka, Croatia \\ Phone: +385 (51) 770447 \\ Fax: +385 (51) 686166 \\ www.intechopen.com
}

\author{
InTech China \\ Unit 405, Office Block, Hotel Equatorial Shanghai \\ No.65, Yan An Road (West), Shanghai, 200040, China \\ 中国上海市延安西路65号上海国际贵都大饭店办公楼 405 单元 \\ Phone: +86-21-62489820 \\ Fax: +86-21-62489821
}


(C) 2012 The Author(s). Licensee IntechOpen. This is an open access article distributed under the terms of the Creative Commons Attribution 3.0 License, which permits unrestricted use, distribution, and reproduction in any medium, provided the original work is properly cited. 